* Corresponding author

Phone +421556022846

E-mail address: silvia.gasincova@tuke.sk

(Ing. Silvia Gašincová, PhD.)

Article information

Article history: AMS-Volume16-No.1-00141-12

Received 14 January 2012

Accepted 25 February 2012

\section{Positional Adjustment for Setting Highway Network of the D1 Motorway Section Mengusovce-Jánovce}

\author{
Silvia Gašincová* , Juraj Gašinec
}

Faculty of Mining, Ecology, Procces Control and Geotechnology, Technical univerzity of Košice, Institute of Geodesy, Cartography and Geographic Information Systems, Park Komenského 19, 04001 Košice

\section{BIOGRAPHICAL NOTES}

Silvia Gašincová, MsC., PhD. ( born 1974) graduated from the Faculty of Mining Ecology, Process Control and Getotechnolgy of Technical University in Košice. University study completed state final examination in 1997 in the field Surveying, Geodesy and Cartography. Since 1999 he has been a lecturer at the Institute of Geodesy, Cartography and Geographic Information Systems, Faculty of Mining Ecology, Process Control and Getotechnolgy at the Technical University in Košice. In 2007 she defended her doctoral dissertation on "Processing of 2D networks using robust methods" and got the scientific-pedagogical degree PhD. In 2010 got the competence for the performance of mining revenue meter under the Ministry of Economy No.1/1993. She is co-authored three college textbooks based on the issues of Land and 30 publications dealing with the problems of processing the results of geodetic measurements odhadovacími alternative methods.

assoc. prof. Juraj Gašinec, MSc., PhD. (born 1971) is graduated Faculty of Mining, Ecology, Process Control and Geotechnology at the Technical University of Košice. Since 1994, he began work as assistant in the Department of Geodesy and Geophysics, today the Institute of Geodesy, Cartography and Geographic Information Systems. In 2004 he defended his doctoral dissertation on the subject, "Creation and analysis of the local geodetic networks". In 2005 he obtained Assoc, prof. degree. Since 2007 to to the present he is the director at the Institute of Geodesy, Cartography and Geographic Information Systems at the Faculty of Mining, Ecology, Process Control and Geotechnology and vice-dean for pedagogical activity in the first level of university education. Special attention deals with problems of of statistical processing of geodetic networks. $\mathrm{He}$ is co-author of the software used in practice, GeoNet, which is used to verification and the processing the geodetic measurement and demonstrate causal relationships between the positional configuration of geodetic network and an realization vector of measured variables.

\section{KEYWORDS}

geodetic network, positional adjustment, indicators of accuracy

\section{ABSTRACT}

TThe D1 motorway is the most important and longest Slovak highway which after its completion will connect the border crossing Bratislava Záhor with the state border with Ukraine via Trnava, Trenčín, Žilina, Poprad, Prešov, Košice and Michalovce. It is part of route "A" 5 of the Pan-European corridor (Trieste) - Bratislava - Žilina - Košice - (Uzhhorod - Lvov) and European routes E50, E58, E75, E442 and E571. The D1 motorway has 
been under construction since 1972, and currently nearly $320 \mathrm{~km}$ long track is in operation, which is less than $62 \%$ of the total planned length of 515.621 kilometers. The present paper deals with the issue of building a surveying network for the construction of a highway bridge 202-00 in the D1 motorway section between Mengusovce-Jánovce followed by statistical and graphical interpretation of the positional measurement

\section{Introduction}

Analysis of the structure of the road network of the Slovak republic indicates the need to connect the west and east of Slovakia with a quality network of motorways and expressways [6],[7]. The problem of building geodetic networks and their subsequent processing is an essential part of engineering surveying. Engineering geodesy is also of major importance in building surveying networks in the construction of large engineering structures including bridges. The purpose of the present paper is to provide readers with an overview of the building of a surveying network for the highway bridge 202-00 in 1.235-1.494 km above the river
Poprad on D1 motorway from Mengusovce to Jánovce and to choose an optimal solution for estimation of the given network parameters. Building of the surveying network was carried out in two stages. Methods used in the geodetic surveying works were based on gradual establishment of local geodetic networks. In building the network, the emphasis was placed primarily on the accuracy and quality of the surveying and computational work, since the object is the access road to the tunnel Bôrik.

\section{Characteristics of the structure}

The D1 motorway section Mengusovce - Jánovce (Figure 1) has a length of $25.85 \mathrm{~km}$. It is divided into 3 subsections: Mengusovce - Poprad (0.00 $\mathrm{km}$ - $8.00 \mathrm{~km})$, Poprad - Matejovce $(8.00 \mathrm{~km}$ - 14.23 $\mathrm{km})$, Matejovce - Jánovce (14.23 km - $25.85 \mathrm{~km})$. It connects to the D1 section Važec - Mengusovce. The construction of the D1 motorway section Mengusovce-Jánovce began on 9th May 2005, the expected completion date of works was December 2008 .

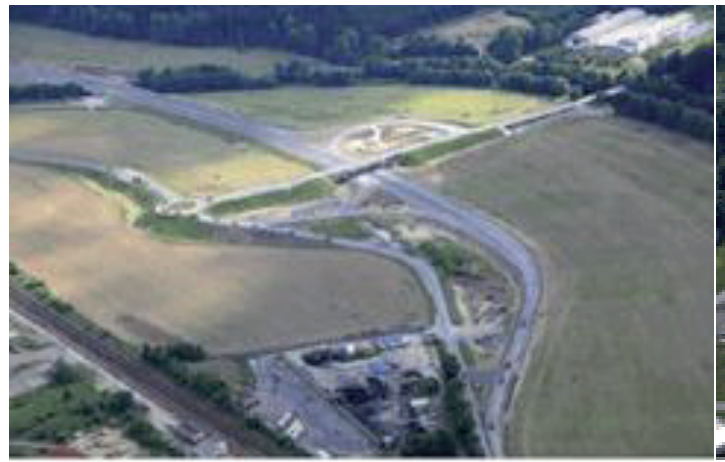

Fig. 1: The motorway section D1 Mengusovce-Jánovce [5].

The bridge structure No 202-00 on the D1 motorway in its $1.235 \mathrm{~km}$ of the route spans over the following obstacles: road P7/40, the inundation area of the river Poprad and adapted bed of the river Poprad. This bridge is also the access road to the tunnel Bôrik (Figure 2) on the east side of the tunnel. The total length of the bridge is $284.07 \mathrm{~m}$. The bridge consists of two main parts, namely of an eleven-span bridge on the left and a ten-span bridge on the right.

The lower part of the bridge structure consists of two abutments and 21 pillars. These bridge ele-

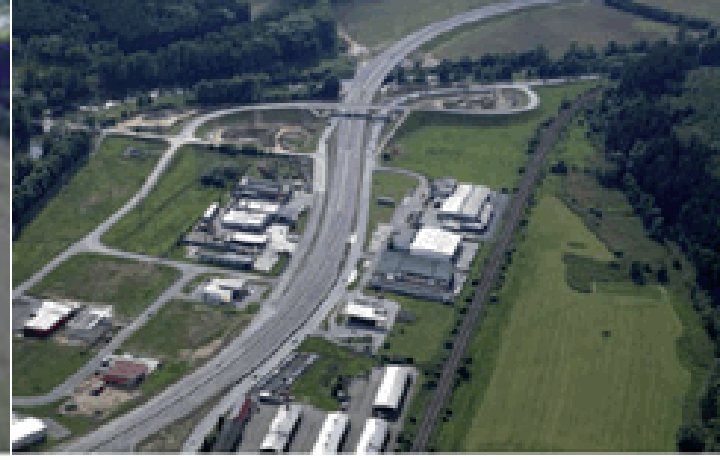

ments are placed on the micropile grate. The steel frame structure is mounted on the PIŽMO supporting construction centering (Figure 3 ) and after welding pins, the entire structure was coupled by a reinforced concrete slab. The PIŽMO material is a demountable steel [10] truss structure adaptable to the type and size of loading, type of the bridge structure, its height and carrying capacity of subsoil, or carrying capacity and the nature of the bottom of water obstructions. The width module of the structure is $2.0 \mathrm{~m}$; the height module is 0.4 $\mathrm{m}$. The PIŽMO pillars can be normally mounted up to 50 metres high or higher [5],[8]. 


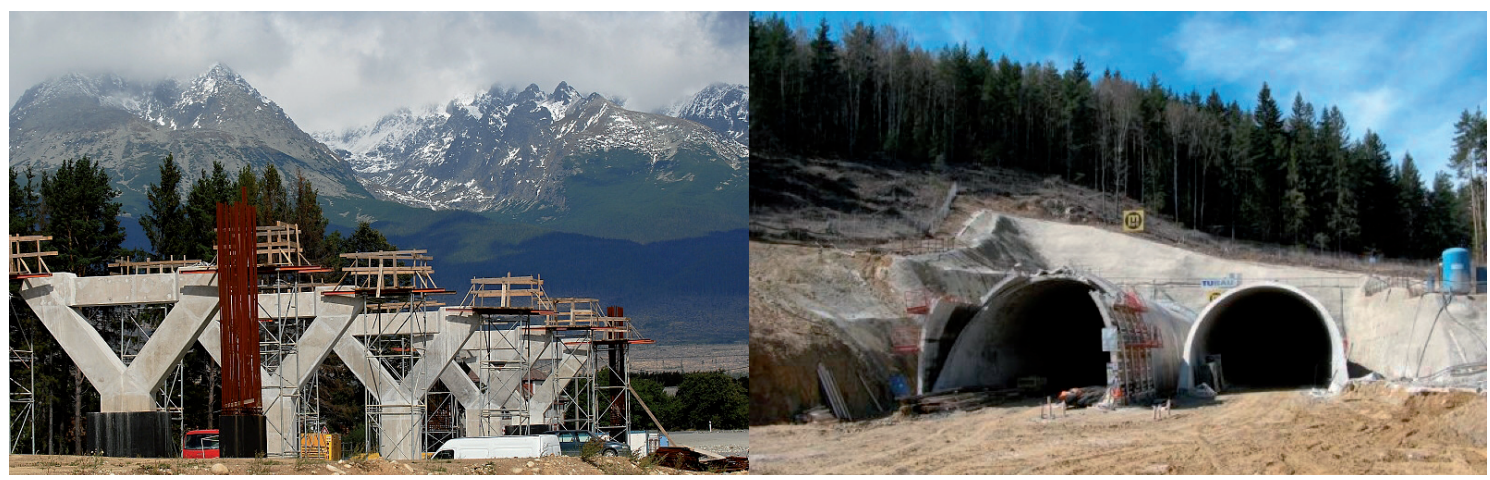

Fig. 2: The pillars of bridges and tunnels during construction Bôrik [4].

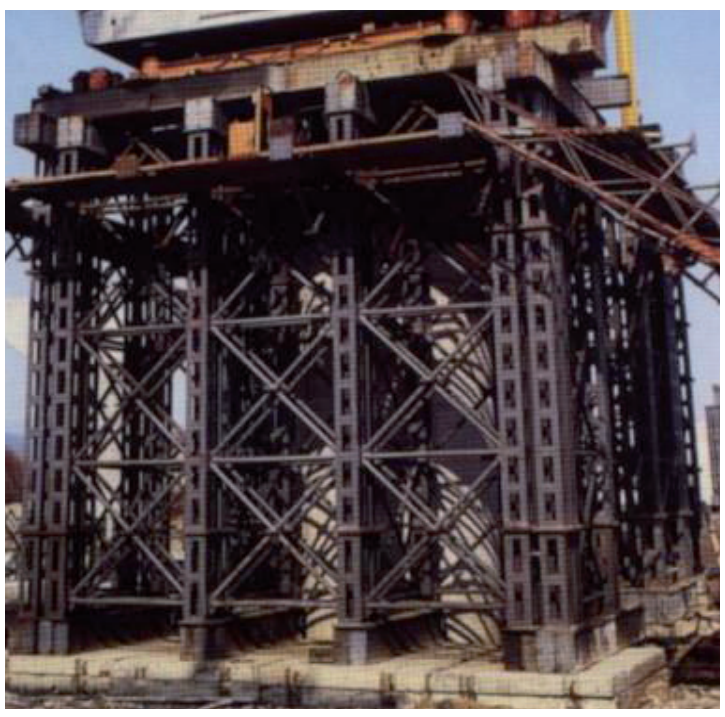

Fig. 3: PIŽMO material [5].

\subsection{Building of setting out network of the bridge}

Given the pace of construction work, the settingout network was built in two stages. These phases differ from each other not only by the time of completion construction work (the first phase in September 2006, second in October 2006), but also by the nature of stabilization and location of the points of the setting-out network. In the first stage of works, the setting-out network consisted of three existing points No 955, 607, 608 and five observation points 2021-2025. Surveying network configuration is shown in (Figure 4).

At this stage of construction work, observation points of the setting-out system were stabilized with concrete blocks with dimensions $1 \times 1 \times 1 \mathrm{~m}$. The concrete block was provided with a nail mark and a ball-shaped head, in the middle of which a hole with a diameter of 1-2 $\mathrm{mm}$ for accurate centra-

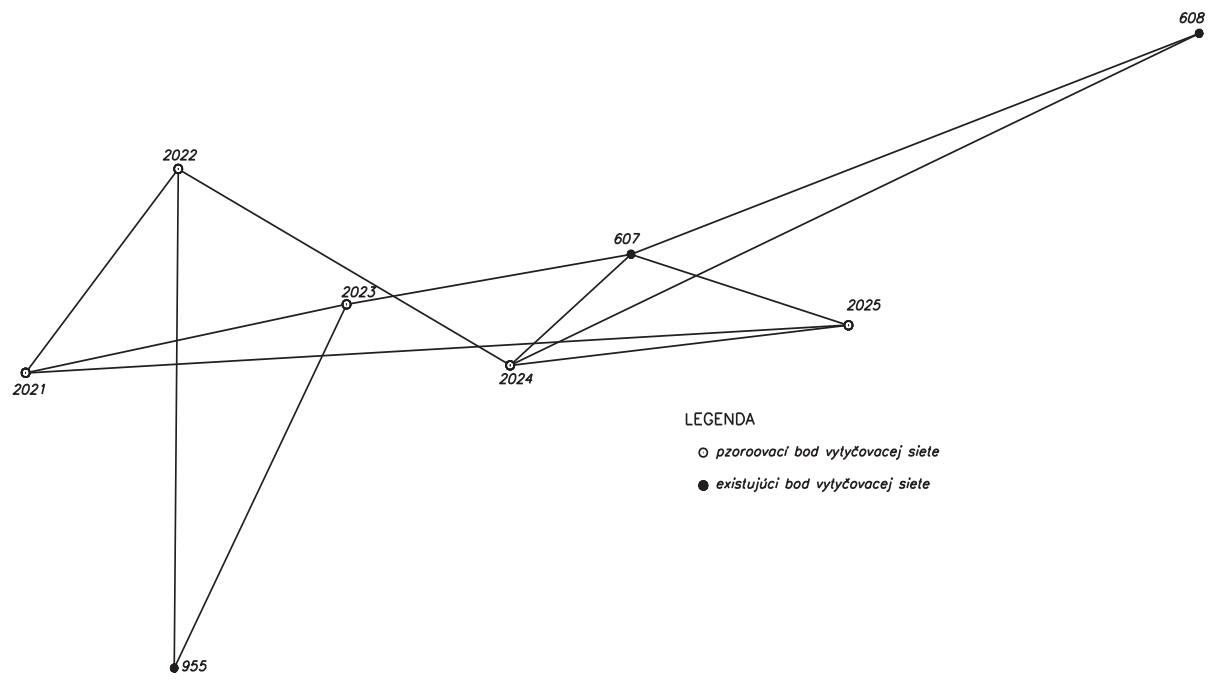

Fig. 4: Configuring setting out network during the first stage of construction work. 
tion of geodetic instruments was drilled. In the first stage of setting-out and computation works, location of the existing points 607,608 and 955 as well as observation points of the setting-out network was determined. Configuring of the network had to be based on the presumption that for setting of the different levels of the bridge structure the polar method would be mostly used from the free position to reduce complicated measurements in setting-out individual parts of the structure as much as possible. The character of the terrain and construction works in the area of building the surveying network in the first stage of construction did not allow to place network setting-out points with stabilized pillars. This led to rebuilding the settingout network (the second stage of construction), which increased the number of observation points by four points from 2026 to 2029 (Figure 5).
These four points were stabilized by stabilization - a lined bore hole (about $1.4 \mathrm{~m}$ above the ground and $3 \mathrm{~m}$ below ground). The pillar was provided with a metal plate with drilled holes with a diameter $16 \mathrm{~mm}$ for forced centration of the device and also pins mark the location of the leveling rod.

The actual location of these four points and the method of stabilization indicate their use not only for setting-out works, but also later after completion for targeting and monitoring of structure deformations. In the second stage of work the location and height of points 2026 to 2029 were determined stablized by pillars as well as of the existing point 954 of the highway setting-out network. In computational processing of the second stage, the position and height of the points determined in the first stage of setting up the setting-out network was considered as invariable.

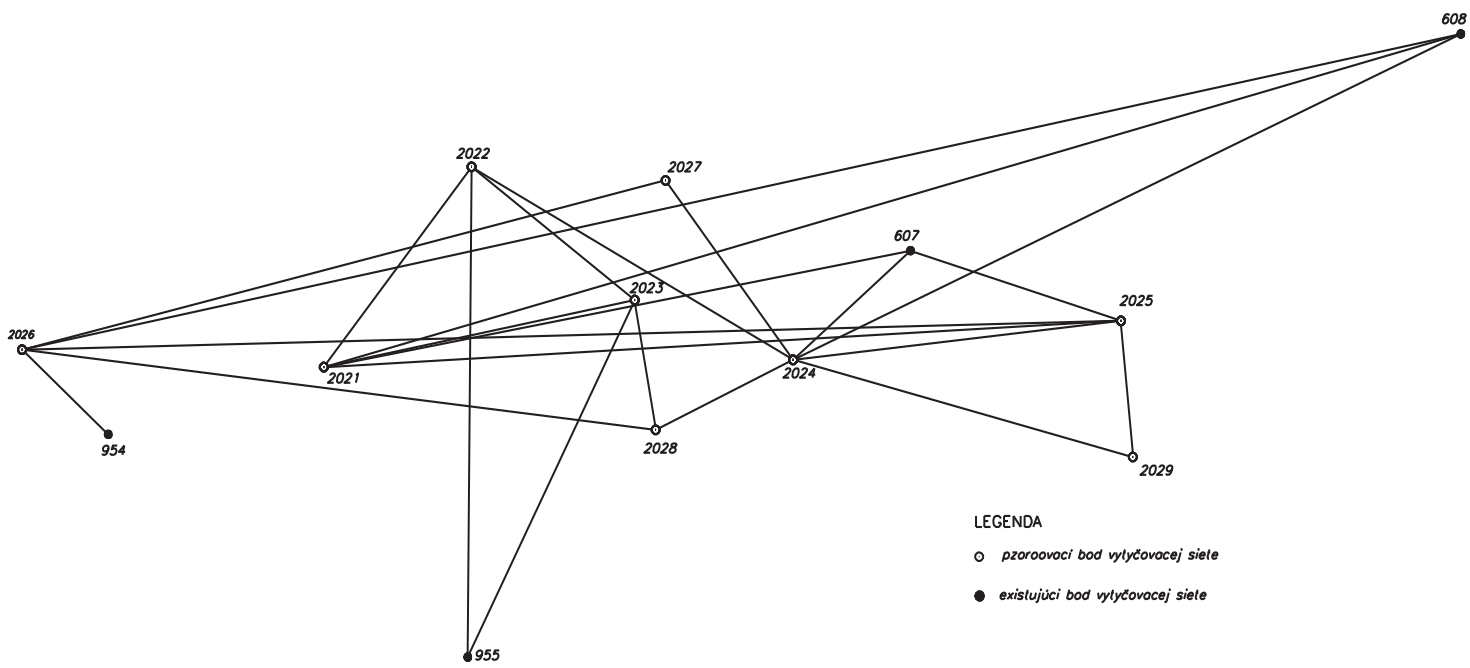

Fig. 5: Configuring the network setting during the second stage of construction work.

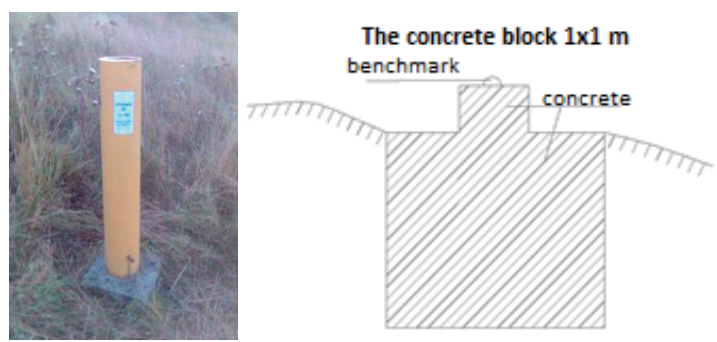

Fig. 6: The pillar for the stabilization of 2026-2029 points and block points to the stabilization of 2021-2025.

\section{Empirical demonstration}

Terrestrial surveying measurements in establishing a setting -out network of the bridge in both stages were carried out to develop a network with universal surveying station LEICA GTS 1205, where the accuracy of angular measurement indicates the standard deviation, which is $15 \mathrm{cc}$ (15 seconds of the centesimal division). The accuracy of length measurement stated by the manufacturer is $2 \mathrm{~mm}$ $+2 \mathrm{ppm}$. It concerns the accuracy of the electrooptical rangefinder, where as a reflective device the prism from TOPCON Company is used. Due to the fact that it was not TOPCON equipment, an ad 
dition constant was set before the measurement itself with the value $4 \mathrm{~mm}$ [3].

\subsection{Positional adjustment of a setting-out network}

When creating a setting-out network we deal with the fact that the new network is more accurate than the base network (motorway setting-out network). Then, when creating such a network it is adjusted as a free (local) network, which is additionally connected to the reference points and positioned. In our case, the reference points set out sections of the motorway $607,608,955$, by which a high internal accuracy of the network is achieved, and at the same time its applicability in the tasks conditioned by the entry of coordinates into the system of the base network. As a method chosen for adjustment of such a network was used the adjustment of the free network using the method of proxy measurements [1],[2], supplemented by the conditions. In geodetic practice, adjustment of measurements is mainly carried out using the method of the least squares, where the well-known relation $\left(\sum p_{i} v_{i}^{2} \equiv \mathrm{v}^{T} \mathrm{Pv}=\min . p_{\mathrm{i}^{\prime}}\right.$ is the weight measurement, $\boldsymbol{P}$ weight matrix) [2] before the actual adjustment can be rewritten as a matrix.

Relations between measured and unknown variables are expressed by the function:

$$
1_{i}+\mathrm{v}_{i}=f\left(\hat{\Theta}_{1}, \hat{\Theta}_{2}, \ldots . \hat{\Theta}_{k}\right) \quad \text { for } \quad i=1,2,3 \ldots k,(1)
$$

where: $\boldsymbol{l}_{\mathrm{i}}$ is a measured quantity - realization of random variable $\boldsymbol{L}_{\mathrm{i}^{\prime}} \boldsymbol{\nu}_{\mathrm{i}}$ is the vector of corrections and $\hat{\boldsymbol{\Theta}}_{i}$ adjustment of (unknown) variable - parametres (coordinates in the calculations are usually determined by the coordinates of the points labelled with symbol $\boldsymbol{C}$, from the English word coordinate). If the function (1) is non-linear, corrections are introduced into the approximate equation (preliminary) values of unknown variables $\Theta_{i}^{0}$ and unknown additions (supplements) $d \Theta_{i}$ that are with the unknown variables in the relation:

$$
\begin{aligned}
& \hat{\Theta}_{1}=\Theta_{1}^{0}+d \hat{\Theta}_{1}, \hat{\Theta}_{2}=\hat{\Theta}_{2}^{0}+d \hat{\Theta}_{2}, \\
& \hat{\Theta}_{k}=\hat{\Theta}_{k}^{0}+d \hat{\Theta}_{k},
\end{aligned}
$$

The functional relation

$$
\nu_{i}=f\left(\hat{\Theta}_{1}^{0}+d \hat{\Theta}_{1}, \Theta_{2}^{0}+d \hat{\Theta}_{2}, \hat{\Theta}_{2}^{0}+d \hat{\Theta}_{2}\right)-l_{i}
$$

is linearized by the development of the Taylor series limited to members of the first order based on the assumption that the approximate values of unknown variables are a good estimate of the unknown ones and the additions (supplements) have small values. Then, partial derivatives of higher orders are close to zero and are neglected. Development of the function (3) in the Taylor series then looks like this:

$v_{i}=f\left(\Theta_{1}^{0}, \Theta_{2}^{0}, \cdots \Theta_{k}^{0}\right)+\frac{\partial L_{i}}{\partial \Theta_{1}} d \hat{\Theta}_{1}+\frac{\partial L_{i}}{\partial \Theta_{2}} d \hat{\Theta}_{2}+$

$\cdots+\frac{\partial L_{i}}{\partial \Theta_{k}} d \hat{\Theta}_{k}-L_{i}$

If members of the Taylor series are replaced by the variables

$$
\begin{aligned}
& \frac{\partial L_{i}}{\partial \hat{\Theta}_{1}}=a_{i}, \frac{\partial L_{i}}{\partial \hat{\Theta}_{2}}=b_{i}, \ldots \ldots ., \frac{\partial L_{i}}{\partial \hat{\Theta}_{\mathrm{k}}}= \\
& =z_{i}, l_{\mathrm{i}}-\mathrm{f}\left(\Theta_{1}^{0}, \Theta_{2}^{0}, \ldots, \Theta_{\mathrm{k}}^{0}\right)=d l
\end{aligned}
$$

the transformed equation of corrections $\nu_{i}$ is as follows:

$v_{i}=a_{i} d \hat{\Theta}_{1}+b_{i} d \hat{\Theta}_{2}+\cdots+z_{i} d \hat{\Theta}_{k}-d l_{i}$

In the matrix entry the equation of corrections looks like this:

$v=\mathbf{A} d \hat{\boldsymbol{\Theta}}-d \mathbf{l}$,
$\mathrm{V}_{(n, 1)}=\left[\begin{array}{c}v_{1} \\ v_{2} \\ \vdots \\ v_{n}\end{array}\right]$,

vector correction

$\mathrm{d} \hat{\boldsymbol{\Theta}}_{(k, 1)}=\left[\begin{array}{c}d \hat{\Theta}_{1} \\ d \hat{\Theta}_{2} \\ \vdots \\ \hat{\Theta}_{k}\end{array}\right]$, the vector of unknown supplements
$\mathbf{A}_{(n, k)}=\left[\begin{array}{cccc}a_{1} & b_{1} & \cdot & z_{1} \\ a_{2} & b_{2} & \cdot & z_{2} \\ \cdot & \cdot & \cdot & \cdot \\ a_{n} & b_{n} & \cdot & z_{n}\end{array}\right]$,

configuration matrix

$$
d \mathbf{l}_{(n, 1)}=\left[\begin{array}{c}
d l_{1} \\
d l_{2} \\
\vdots \\
d l_{k}
\end{array}\right]
$$

reduced measurement vector
The number of equations of correction is identical to the number of measured quantitty $\mathrm{n}$ and $\mathrm{k}$ is the number of unknown parameters $\Theta$. To calculate the extreme value of the function it is necessary to differentiate unknown variables according to the vector $d \Theta$ and set equal to zero, i.e. is assignment to the condition of minimum and subsequent derivation $\frac{\partial \mathbf{v}^{r} \mathbf{P} \mathbf{v}}{\partial d \hat{\boldsymbol{\Theta}}}$ results in the system of normal equations expressed as:

$$
\mathbf{A}^{\mathrm{T}} \mathbf{P} \mathbf{A} d \hat{\boldsymbol{\Theta}}-\mathbf{A}^{\mathrm{T}} \mathbf{P} d \mathbf{l}=\mathbf{0}
$$

The equation can be expressed in a short form as 


\section{$\mathbf{N} d \hat{\boldsymbol{\Theta}}-\mathbf{A}^{\mathrm{T}} \mathbf{P} \quad d \mathbf{l}=\mathbf{0}$}

where the matrix of coefficients of normal equations $\mathrm{N}$ is always square and symmetric.

The solution of normal equations will be:

$$
d \hat{\boldsymbol{\Theta}}=\mathbf{N}^{-1} \mathbf{A}^{T} \mathbf{P} d \mathbf{l}
$$

From the equations of corrections, the aposteriori standard deviation is calculated:

$s_{0}=\sqrt{\frac{\mathbf{v}^{T} \mathbf{P} \mathbf{v}}{r}}$

where the variable $r=n-k$ gives the number of redundant measuremets. Estimation of the vector of variances for adjusted unknown quatities $\hat{\boldsymbol{\Theta}}=\boldsymbol{\Theta}^{0}+d \hat{\boldsymbol{\Theta}}$ is given by the diagonal of the covari-

$\sum_{\hat{\Theta}}=s_{0}^{2} \mathrm{Q}_{\hat{\Theta}}$

ance matrix $\Sigma_{\hat{\Theta}}$ :

where cofactor matrix for unknown parametres Qe equals inverse matrix $N^{-1}$ of the coefficient of normal equations. Relations (7) and (12) present the so-called Gauss-Markov model. As mentioned above in this chapter, a particular setting-out network of the structure was processed as a free network.

The adjustment procedure was chosen because the configuration matrix (matrix $A$ ) was singular, which means that its value $\mathbf{h}$ is $h\left(\mathrm{~A}_{(n, m)}\right)=h<m<n$, where $\mathbf{m}$ is the number of unknown parameters (parameters of adjustment) and $\mathbf{n}$ is the number of measurements. The value $\mathbf{h}=\mathrm{h}(\mathrm{A})$ matrix $\boldsymbol{A}_{(n, m)}$ called the maximum number of linearly independent row vectors, which is equal to the maximum number of linearly independent vectors of matrix $A$. In this adjustment we proceed like in the adjustment with intermediate values for binding adjustmentt. The difference is that matrix $\mathrm{A}$ is singular and should be added when calculating matrix $\mathrm{F}$.

Matrix $\mathrm{F}$ is a matrix whose composition depends on the structure of the matrix coefficients of corrections and reformulations of equations (matrix plan), this means that it depends on the network configuration. The size of this matrix is defined by the defect of the value of matrix $N d$ and the number $m$ of unknown parameters (coordinates of points). Matrix $\mathrm{F}$ has thus the size $(d, m)$. Basically, this is a matrix representing conditions. The number of conditions is identical with the value $d$, which in turn is identical to the number of rows in the matrix. In our case, there are three rows, three conditions as it is the network with measured lengths and pointers that is adjusted.

For positional triangulation network with free measired lengths, or measured lengths and pointers

$$
\mathrm{F}_{(3, m)}=\left(\begin{array}{ccccccc}
1 & 0 & 1 & 0 & \cdots & 1 & 0 \\
0 & 1 & 0 & 1 & \cdots & 0 & 1 \\
-y_{01} & x_{01} & -y_{02} & x_{02} & \cdots & -y_{0 k} & x_{0 k}
\end{array}\right)
$$

with defect $\mathrm{d}=3$ matrixe $F$ is:

where: $\mathrm{k}=\mathrm{m} / \mathrm{D}$ ( $\mathrm{D}$ is network size). For the matrix of coefficients of normal equations for the free net-

$$
\overline{\mathbf{N}}=\mathbf{A}^{T} \mathbf{P A}+\mathbf{F}^{T} \mathbf{F}
$$

work then it is:

Subsequently, we calculate $d \hat{\mathbf{C}}$ and vector to cor-

$$
\begin{aligned}
& d \hat{C}=\overline{\boldsymbol{N}}^{-1} \boldsymbol{A}^{T} \boldsymbol{P} d \boldsymbol{l}-\overline{\boldsymbol{N}}^{-1} \boldsymbol{F}^{T} \boldsymbol{k} \\
& \boldsymbol{k}=\left(\overline{\boldsymbol{F}}^{-1} \boldsymbol{F}^{T}\right) \boldsymbol{F}^{-1} \boldsymbol{A}^{T} \boldsymbol{P} d \boldsymbol{l}
\end{aligned}
$$

relate $\mathrm{k}$

The covariance matrix of the vector of adjusted quantities is obtained by application of the law of

$\Sigma_{C}=\left(A^{T} P A+F^{T} F\right)^{-1} A^{T} P \sigma_{0}^{2} P^{-1}\left[\left(A^{T} P A+F^{T} F\right)^{-1} A^{T} P\right]^{T}(16)$

accumulation of mean errors:

The unit mean error is calculated from the relation $s_{0}=\sqrt{\frac{v^{t} P v}{r}}$. Mean errors of the measured variables are calculated from the relation $s_{i}=s_{0} \sqrt{Q_{i i t i}}$, where $Q_{\text {lili }}$ are weight coefficients on the diagonal matrix cofactors of the measured variables $Q$. Mean coordinate errors calculated from the elements on the main diagonal covariance matrix of the adjusted variables (coordinates) $s_{x}=\sqrt{\sum_{x x}}, s_{y}=\sqrt{\sum_{y y}}$.

The accuracy of the setting-out network was assessed on the basis of local and global indicators of accuracy. Global indicators characterize the accuracy of the network as a whole, serve for comparing network, binding locally to individual points of the network, or to two or three points of the network. Local indicators of accuracy are divided into: spatial (area) which include absolute confidence ellipses, relative error ellipses. Absolute confidence ellipses represent a random area that covers the actual position of a point with a probability [9] $\mathrm{p}=1-\alpha$ where 
$\alpha$ represents the level of significance. The relative error ellipse refers to a pair of points which define a random space [2]. Indicators of accuracy include mean positional error of the point and mean coordinate error of the point of the geodetic network.

\subsubsection{Results of positional adjustment of a setting-out} network in the first stage of the network construction
Location: Structure 202 - Bôrik

Date: 09.2006

Stage: First

Measured variables: length and direction

Number of measurements: 36

Number of adjustment coordinates: 16

Number of links: 3

Total number of points: 8 and of these: Free points: 8

Table 1: Approximate and adjusted coordinates for the setting-out network of the stucture.

\begin{tabular}{|c|c|c|c|c|c|c|}
\hline \multirow{2}{*}{ Point number } & \multicolumn{2}{|c|}{ Approximate coordinates } & \multicolumn{2}{c|}{ Vector $d \hat{C}$} \\
& $\dot{X} \mathbf{~} \mathbf{m}]$ & $\dot{Y}$ [m] & $d \hat{X}$ [mm] & $d \hat{Y}$ [mm] & $\hat{X}$ [m] & $\hat{Y}$ [m] \\
\hline $\mathbf{2 0 2 1}$ & 1196775.867 & 340882.449 & 9.421 & 2.134 & 1196775.8764 & 340882.4511 \\
\hline $\mathbf{2 0 2 2}$ & 1196724.540 & 340841.744 & -4.177 & -2.508 & 1196724.5358 & 340841.7415 \\
\hline $\mathbf{2 0 2 3}$ & 1196758.659 & 340796.828 & -0.063 & -2.995 & 1196758.6589 & 340796.8250 \\
\hline $\mathbf{2 0 2 4}$ & 1196773.946 & 340753.218 & 1.140 & -0.309 & 1196773.9471 & 340753.2177 \\
\hline $\mathbf{2 0 2 5}$ & 1196763.936 & 340663.019 & -1.421 & -0.683 & 1196763.9346 & 340663.0183 \\
\hline $\mathbf{6 0 7}$ & 1196746.020 & 340720.980 & 0.039 & -0.180 & 1196746.0200 & 340720.9798 \\
\hline $\mathbf{6 0 8}$ & 1196690.470 & 340569.470 & -8.165 & -13.954 & 1196690.4618 & 340569.4560 \\
\hline $\mathbf{9 5 5}$ & 1196850.230 & 340842.800 & 3.226 & 18.494 & 1196850.2332 & 340842.8185 \\
\hline
\end{tabular}

Table 2: Qualitative evaluation of the setting-out network.

\begin{tabular}{|c|c|c|c|c|c|}
\hline Point number & Binding & $\mathbf{s}_{x}[\mathrm{~mm}]$ & $s_{y}[\mathrm{~mm}]$ & $s_{x y}[\mathrm{~mm}]$ & $s_{p}[\mathrm{~mm}]$ \\
\hline 2021 & free & 0.892 & 0.866 & 0.88 & 1.24 \\
\hline 2022 & free & 0.701 & 1.169 & 0.96 & 1.36 \\
\hline 2023 & free & 1.137 & 0.944 & 1.04 & 1.48 \\
\hline 2024 & free & 0.695 & 0.911 & 0.81 & 1.15 \\
\hline 2025 & free & 0.946 & 1.208 & 1.09 & 1.53 \\
\hline 607 & free & 0.628 & 0.798 & 0.72 & 1.02 \\
\hline 608 & free & 1.168 & 1.292 & 1.23 & 1.74 \\
\hline 955 & free & 1.323 & 1.706 & 1.53 & 2.16 \\
\hline
\end{tabular}

Table 3: Absolute standard ellipses.

\begin{tabular}{|c|c|c|c|c|}
\hline Point number & \multicolumn{2}{|c|}{ Binding } & \multicolumn{1}{c|}{$\boldsymbol{b}$ [mm] } & bearing [g] \\
\hline $\mathbf{2 0 2 1}$ & free & 0.959 & 0.791 & 45.200 \\
\hline $\mathbf{2 0 2 2}$ & free & 1.171 & 0.697 & -95.382 \\
\hline $\mathbf{2 0 2 3}$ & free & 1.177 & 0.893 & -25.971 \\
\hline $\mathbf{2 0 2 4}$ & free & 0.914 & 0.692 & 92.114 \\
\hline $\mathbf{2 0 2 5}$ & free & 1.218 & 0.933 & -86.961 \\
\hline $\mathbf{6 0 7}$ & free & 0.808 & 0.615 & 84.606 \\
\hline $\mathbf{6 0 8}$ & free & 1.348 & 1.103 & 66.932 \\
\hline $\mathbf{9 5 5}$ & free & 1.749 & 1.266 & 79.408 \\
\hline
\end{tabular}




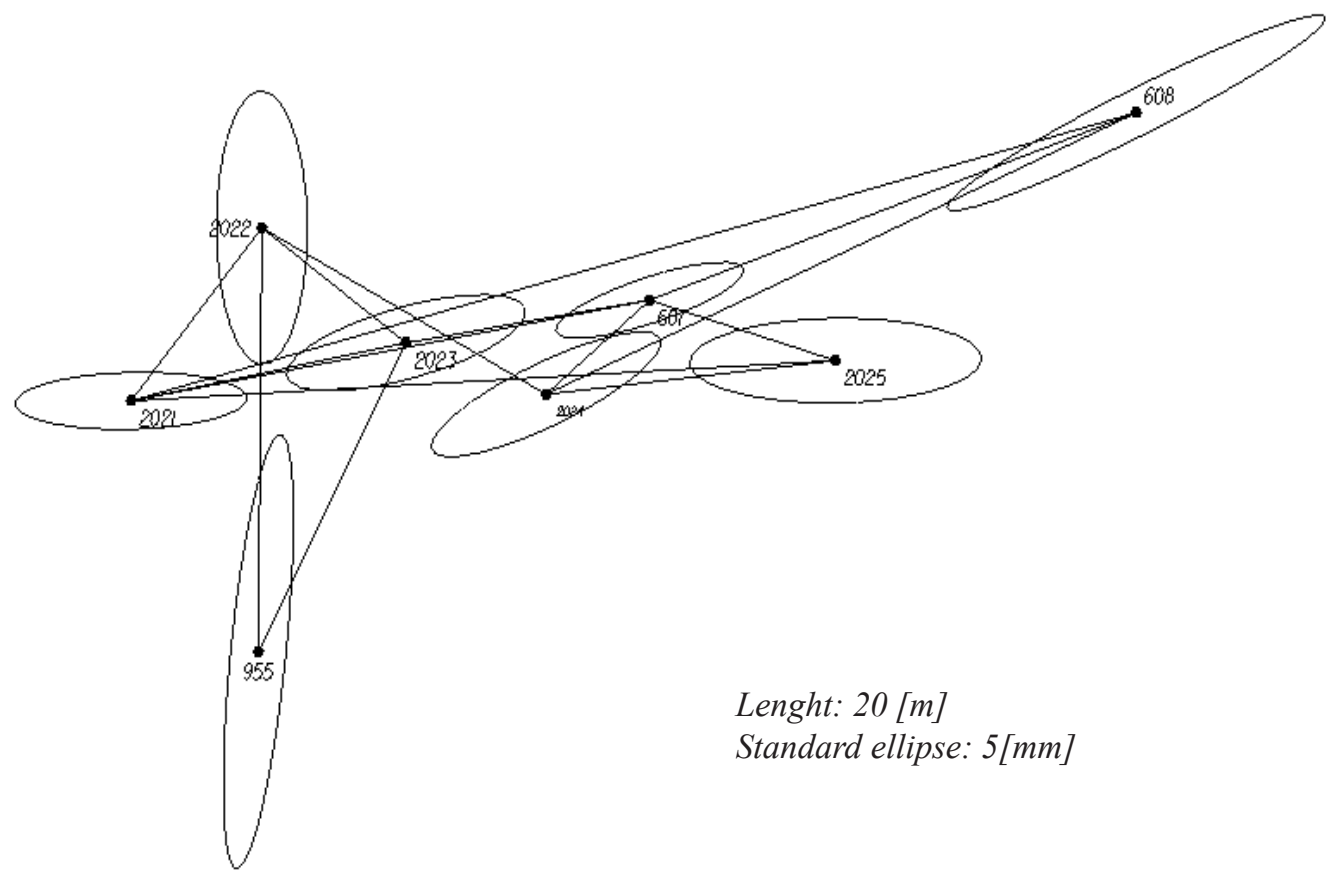

Fig. 7: View of standard error ellipses in the first stage of network building.

3.1.2 Results of positional adjustment of the setting- Measured variables: length and direction out network in the second stage of the network conNumber of measurements: 55

\section{struction}

Location: Structure 202 - Bôrik

Number of adjustment coordinates: 14

Number of links: 12

Date: 10.2006

Total number of points: 13 and of these: 7 Free points: 6

\section{Stage: Second}

Table 4: Approximate and adjusted coordinates for the setting-out network.

\begin{tabular}{|c|c|c|c|c|c|c|}
\hline \multirow{2}{*}{ Point number } & \multicolumn{2}{c}{ Approximate coordinates } & \multicolumn{4}{c|}{ Vector $d \hat{C}$} \\
$\mathbf{X}$ [m] & $\dot{Y}$ [m] & $d \hat{X}$ [mm] & $d \hat{Y}$ [mm] & $\hat{X}$ [m] & $\hat{Y}$ [m] \\
\hline $\mathbf{2 0 2 1}$ & 1196775.8670 & 340882.4490 & 0.000 & 0.000 & 1196775.8670 & 340882.4490 \\
\hline $\mathbf{2 0 2 2}$ & 1196724.5400 & 340841.7440 & 0.000 & 0.000 & 1196724.5400 & 340841.7440 \\
\hline $\mathbf{2 0 2 3}$ & 1196758.6589 & 340796.8250 & 0.000 & 0.000 & 1196758.6589 & 340796.8250 \\
\hline $\mathbf{2 0 2 4}$ & 1196773.9471 & 340753.2177 & 0.000 & 0.000 & 1196773.9471 & 340753.2177 \\
\hline $\mathbf{2 0 2 5}$ & 1196763.9346 & 340663.0183 & 0.000 & 0.000 & 1196763.9346 & 340663.0183 \\
\hline $\mathbf{6 0 7}$ & 1196746.0200 & 340720.9798 & -0.603 & -0.808 & 1196746.0194 & 340720.9790 \\
\hline $\mathbf{6 0 8}$ & 1196690.4618 & 340569.4560 & 0.000 & 0.000 & 1196690.4618 & 340569.4560 \\
\hline $\mathbf{9 5 5}$ & 1196850.2332 & 340842.8185 & 1.170 & 2.405 & 1196850.2344 & 340842.8209 \\
\hline $\mathbf{9 5 4}$ & 1196793.1720 & 340941.8120 & -1.885 & 7.549 & 1196793.1701 & 340941.8195 \\
\hline $\mathbf{2 0 2 6}$ & 1196771.3268 & 340965.4760 & 2.454 & 3.997 & 1196771.3293 & 340965.4800 \\
\hline $\mathbf{2 0 2 7}$ & 1196727.9424 & 340788.4169 & 1.025 & 3.437 & 1196727.9434 & 340788.4203 \\
\hline $\mathbf{2 0 2 8}$ & 1196791.8896 & 340791.0781 & 0.833 & -0.408 & 1196791.8904 & 340791.0777 \\
\hline $\mathbf{2 0 2 9}$ & 1196798.8229 & 340659.7544 & 3.224 & -0.438 & 1196798.8261 & 340659.7540 \\
\hline
\end{tabular}


Table 5: Qualitative evaluation of the setting-out network in the second stage of construction.

\begin{tabular}{|c|c|c|c|c|c|}
\hline Point number & Binding & $s_{x}[m m]$ & $s_{y}[\mathrm{~mm}]$ & $s_{x y}[\mathrm{~mm}]$ & $s_{p}[\mathrm{~mm}]$ \\
\hline 2021 & fixed point & 0.000 & 0.000 & 0.000 & 0.000 \\
\hline 2022 & fixed point & 0.000 & 0.000 & 0.000 & 0.000 \\
\hline 2023 & fixed point & 0.000 & 0.000 & 0.000 & 0.000 \\
\hline 2024 & fixed point & 0.000 & 0.000 & 0.000 & 0.000 \\
\hline 2025 & fixed point & 0.000 & 0.000 & 0.000 & 0.000 \\
\hline 607 & free & 1.106 & 1.859 & 1.53 & 2.16 \\
\hline 608 & fixed point & 0.000 & 0.000 & 0.000 & 0.000 \\
\hline 955 & free & 6.315 & 3.752 & 5.19 & 7.35 \\
\hline 954 & free & 11.885 & 9.586 & 10.80 & 15.27 \\
\hline 2026 & free & 11.504 & 6.045 & 9.19 & 13.00 \\
\hline 2027 & free & 5.763 & 4.646 & 5.23 & 7.40 \\
\hline 2028 & free & 3.567 & 6.898 & 5.49 & 7.77 \\
\hline 2029 & free & 3.074 & 1.115 & 2.31 & 3.27 \\
\hline
\end{tabular}

Table 6: Absolute standard ellipses.

\begin{tabular}{|c|c|c|c|c|}
\hline Point number & \multicolumn{2}{|c|}{ Binding $\mathbf{m m}]$} & \multicolumn{1}{c|}{ bearing [g] } \\
\hline $\mathbf{6 0 7}$ & free & 1.952 & 0.932 & 77.429 \\
\hline $\mathbf{9 5 5}$ & free & 6.526 & 3.371 & 19.043 \\
\hline $\mathbf{9 5 4}$ & free & 13.743 & 6.654 & -38.911 \\
\hline $\mathbf{2 0 2 6}$ & free & 11.568 & 5.922 & -7.789 \\
\hline $\mathbf{2 0 2 7}$ & free & 7.073 & 2.182 & -41.731 \\
\hline $\mathbf{2 0 2 8}$ & free & 7.601 & 1.590 & 71.737 \\
\hline $\mathbf{2 0 2 9}$ & free & 3.075 & 1.112 & 1.903 \\
\hline
\end{tabular}

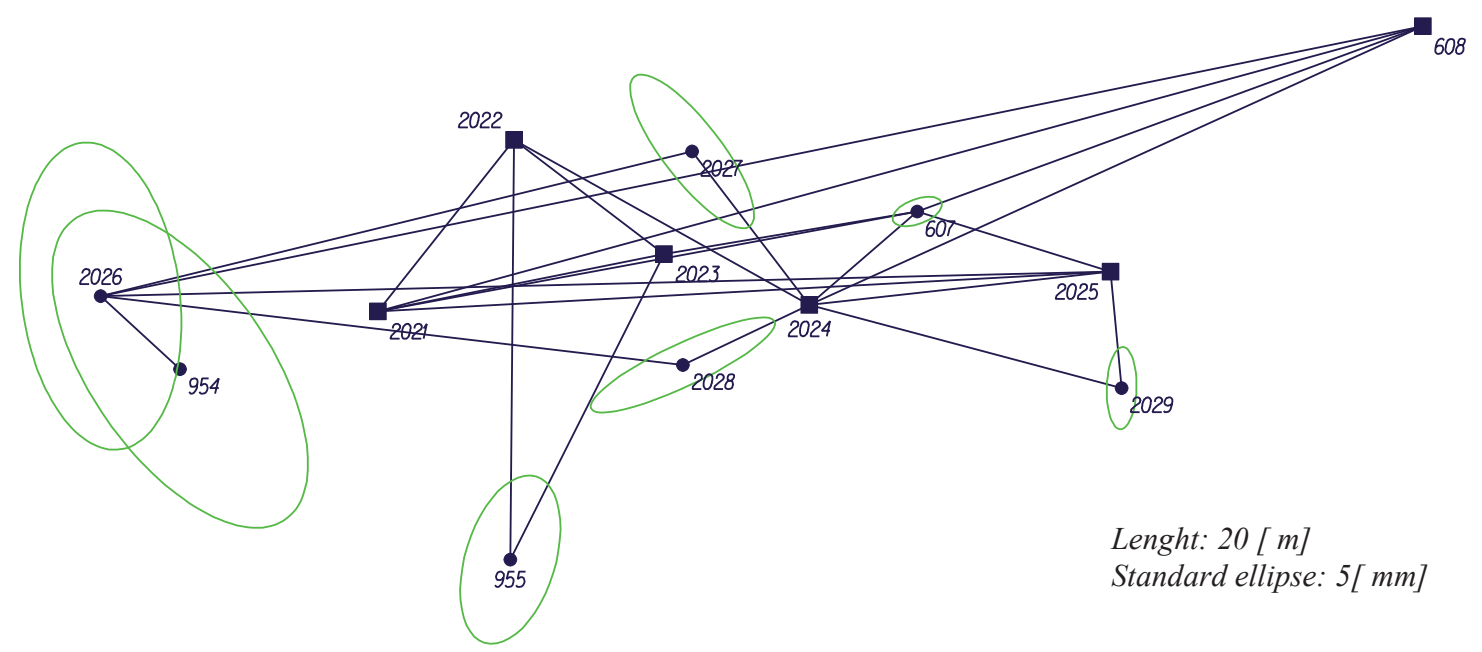

Fig. 8: View of standard error ellipses in the second stage of network construction. 
The values of ellipse parameters, i.e. major, minor half-axis of the ellipse and bearing rotation were determined using the relations given in [2],[3]. Graphical interpretation of the obtained circuit parameters of accuracy in the second stage of building the setting-out network of the bridge is shown in Figure 8.

\section{Conclusion}

The present paper has shown the importance of building setting-out networks [1], which should constitute a sufficiently reliable and accurate basis for the development of major engineering works. On the basis of the calculated global characteristics of accuracy, we can conclude that the geodetic setting-out network established after the first stage was sufficiently reliable. It was different though in the second stage of building the network, where the mean value of the coordinate errors and mean positional errors in the network showed significant deterioration of the accuracy and reliability of the network compared to the values from the first stage. This impairment of positional accuracy led to the conclusion that indicated the need for having to perform a quasi third stage. In fact, this third stage was carried out, which resulted in improving the positional accuracy characteristics of the settingout network. D1 motorway section Mengusovce Jánovce is now fully operational, it was opened for public use as a full-profile highway in September 2009.

\section{References}

[1] BAJTALA, M., SOKOL, Š:: Odhad variančných komponentov z meraní v geodetickej sieti. Acta Montanistica Slovaca, roč.2, č.10, s. 68 - 77, Košice, 2005, ISSN 1335-1335-1788

[2] BÖHM, J., RADOUCH, V., HAMPACHER, M.: Teorie chyb a vyrovnávací počet, Praha, Geodetický a kartografický podnik, 1990.

[3] DOBEŠ, J. : Presné lokálne geodetické siete. Bratislava, 1990, S. 175.

[4] KASANICKÝ, G., GRENDEL,P., MARASOVÁ,D.: Legislatíva bezpečnosti tunelov $\vee$ Európskej únii a riziká $\vee$ cestných tuneloch. Transport and Logistics, mimoriadne číslo (2009), s. 82-90, ISSN 1451-107X.

[5] MARASOVÁ, D., TARABA,V., GRENDEL,P.: Legislatíva a jej požiadavky na bezpečnost' tunelov. Acta Montanistica Slovaca, Ročník 15(2010), mimoriadne číslo1, s. 9-13, ISSN 1335-1788

[6] MICHALČÁK, O.: Inžinierska geodézia II., Alfa, Bratislava, 1985.
[7] PLÁNIČKA, F., ŠOLC, M., MAREK, P.: For Partial Factors Design for the SBRA Probablistic Method. Acta Mechanica Slovaca, Vol. 15, No 2, p. 22-27, 2011, ISSN 1335-2393.

[8] SLOTA, J., SPIŠIAK, E.: Determination of Furming-limit Diagrams Considering Various Models for Steel Sheets. Acta Mechanica Slovaca, Vol. 15, No 1, p. 56-63, 2011, ISSN 13352393.

[9] http://www.asb.sk/inzinierske-stavby/dopravne-stavby/ dialnica-d1-sverepec-vrtizer-1-usek-styri-mosty-202-203204-a-205-3472.html.

[10] http://www.tooz.sk/index.php?page=stavebnacinnost\&story=mostne-stavitelstvo\&view=most-montaz-ademontaz-podpier. 